\title{
REVIEW
}

\section{Clinical review: The critical care management of the burn patient}

\author{
Jane A Snell', Ne-Hooi W Loh*2, Tushar Mahambrey ${ }^{3}$ and Kayvan Shokrollahi ${ }^{4}$
}

\begin{abstract}
Between 4 and $22 \%$ of burn patients presenting to the emergency department are admitted to critical care. Burn injury is characterised by a hypermetabolic response with physiologic, catabolic and immune effects. Burn care has seen renewed interest in colloid resuscitation, a change in transfusion practice and the development of anti-catabolic therapies. A literature search was conducted with priority given to review articles, meta-analyses and well-designed large trials; paediatric studies were included where adult studies were lacking with the aim to review the advances in adult intensive care burn management and place them in the general context of day-to-day practical burn management.
\end{abstract}

\section{Introduction}

Burns are common, with the potential for considerable morbidity and mortality. Almost 29,000 patients were admitted to UK burn services between 2003 and 2007 [1]. Between 4 and $22 \%$ were admitted to intensive care from presentation [2] and successful management requires a team approach.

\section{Pathophysiology of burn shock}

Burn injury results in cardiogenic, hypovolaemic and distributive shock. The intravascular volume becomes depleted primarily due to increased capillary permeability and fluid shifts. Above $30 \%$ total body surface area (TBSA), only partial compensation can be achieved by fluid resuscitation due to a generalised reduction in sodium ATPase activity and disruption of the cellular transmembrane ionic gradient that persists for several days. Microvascular injury secondary to inflammatory mediators such as histamine, bradykinin, prostaglandins,

*Correspondence: Will.Loh@gmail.com

${ }^{2}$ Department of Neuroanaesthesia and Critical Care, Horsley ICU, The Walton

Centre for Neurology and Neurosurgery, Liverpool L9 7L, UK

Full list of author information is available at the end of the article leukotrienes, vasoactive amines, platelet activation products and complement allows protein loss into the interstitium. The intravascular colloid osmotic pressure falls and fluid escapes the vascular system. The result is a loss of intravascular fluid, electrolytes and proteins with rapid equilibration with the interstitial compartments. Clinically, this is manifested by hypovolaemia, haemoconcentration, oedema, reduced urine output and cardiovascular dysfunction. Adequate resuscitation from burn shock is a critical therapeutic intervention in burn management.

\section{Fluid resuscitation}

Appropriate fluid management is the foundation of acute burns management. Without early and effective treatment, burns involving greater than 15 to $20 \%$ TBSA will result in hypovolaemic shock [3]. Mortality is increased if resuscitation is delayed longer than 2 hours post burn injury [4]. The aim is to prevent the development of burn shock and to minimise disruption to physiologic parameters in the face of ongoing cellular and hormonal responses. Several formulae have been developed to optimise fluid delivery whilst preventing over-resuscitation and subsequent pulmonary oedema, and potentially compartment syndrome in unburned limbs or abdomen.

There is limited evidence regarding burns resuscitation. The Parkland formula is most widely used and is the current consensus formula. The original Parkland formula included an element of colloid resuscitation but this has been omitted since 1979 due to fears over worsening acute respiratory distress syndrome (ARDS). Whilst formulae are a useful guide, the prescription should be adjusted to each patient. Initial fluid resuscitation is often inappropriate: Collis and colleagues reviewed burn size estimation and fluid prescription in over 300 patients and found that, on average, patients received $150 \%$ of recommended fluid based on the emergency department TBSA estimation, increasing to $200 \%$ after TBSA estimation by the burn unit [5]. Baxter identified some patient groups who routinely required further fluid in addition to that described by the Parkland formula. These groups include patients with inhalation 
injuries, those with electrical burns and those receiving delayed resuscitation [6]. Both Holm and Csontos and colleagues have found evidence suggesting that the Parkland formula is not accurate for predicting fluid requirements and instead suggest other methods and monitoring to guide resuscitation $[7,8]$.

Base deficit and lactate have been shown to correlate with mortality and fluid resuscitation volumes $[9,10]$. Physiologic manipulation, however, does not change outcome; correction of acidosis and restoration of cardiac function takes between 24 and 48 hours irrespective of the resuscitation used [11,12]. It is important for clinicians to regularly review physiological parameters and resuscitation endpoints, particularly urine output. A urine output of 0.5 to $1 \mathrm{ml} / \mathrm{kg} /$ hour, as recommended by the American Burn Association, should be targeted in the adult patient whilst monitoring pulse, blood pressure and oxygen saturations [13]. There is a paucity of evidence indicating the ideal urine output during resuscitation. Certain situations, including electrical or crush injury with associated rhabdomyolysis, merit additional monitoring and fluid loading. A small study comparing permissive hypovolaemia using a haemodynamic-guided approach with retrospective controls who received the Parkland formula found a reduction of volume infusion ( $3.2 \pm 0.7$ vs. $4.6 \pm 0.3 \mathrm{ml} / \mathrm{kg} / \%$ burn, $P<0.001$ ), a reduction in positive fluid balance ( $7.5 \pm 5.4$ vs. $12 \pm 4.7 \mathrm{l} /$ day, $P<0.05)$ and a significant reduction in Multiple Organ Dysfunction Score value $(P=0.003)$ with permissive hypovolaemia [14]. Currently, there is no reliable tool to guide burn shock resuscitation, which has implications for the detection of resuscitation endpoints. Reducing complications of over-resuscitation and under-resuscitation requires ongoing scrutiny from an experienced burn team.

Pruitt has described the phenomenon of excess fluid loading as fluid creep; this is commonly seen. He states that 'adequate resuscitation has been succeeded by fluid creep, producing excessive resuscitation in the apparent belief that if some fluid is good, lots of fluid will be even better' [15]. Fluid creep usually results from inaccuracies in calculating fluid requirement, from clinician inattention to reducing unnecessary fluid infusions, from the increased use of sedation and analgesic infusions, and from the excess administration of crystalloid in favour of colloid replacement - or a combination.

Fluid creep issues have led to re-evaluation of the use of colloid. In theory, colloid resuscitation may preserve plasma oncotic pressure, provide efficient plasma expansion and reduce tissue and pulmonary oedema. An early meta-analysis of burn patients concluded the use of colloids to be deleterious, where the odds ratio for mortality with human albumin solution (HAS) usage was calculated to be as high as 2.40 (95\% confidence limits:
1.11, 5.19) [16]. This review evaluated only four trials involving burns, one of which showed an increase in mortality following the use of HAS. Goodwin and colleagues found colloid-resuscitated patients required less fluid than those who received crystalloid alone (2.98 vs. $3.81 \mathrm{ml} / \mathrm{kg} / \%$ TBSA) and their haemodynamic parameters were improved during the 12-hour to 24-hour period but patients developed progressive accumulation of lung water up to 7 days post burn [17]. Mortality was higher in the colloid group (11/40) than in the crystalloid group (3/39) although these patients eventually died of causes not obviously related to fluid resuscitation.

A multicentre randomised control trial involving 42 burn patients found no increase in multiple organ failure rates or mortality following the administration of $5 \%$ HAS for burn shock resuscitation [18]. Cochran and colleagues completed a retrospective analysis of patients who received albumin resuscitation compared with a control group who did not receive albumin [19]. After controlling for age, TBSA of burn and inhalation injury, albumin resuscitation did not significantly reduce mortality (odds ratio $=1.90,95 \%$ confidence interval $=$ 0.85 to 4.22 ). HAS is available at $5 \%$ and $20 \%$ formulations, and there is insufficient evidence to determine which might be most appropriate. Some consider the two formulations to be radically different and maintain that a study on $20 \%$ albumin in burns resuscitation is sorely needed.

There continues to be no consensus regarding the timing of colloid initiation. Fluid extravasation has been shown to stop by 8 to 12 hours, and Holm believes there is no evidence to indicate the need to delay colloid administration beyond this. Early colloid actually appears to have a pulmonary volume-sparing benefit [7]. O'Mara and colleagues randomised patients to either a plasma or crystalloid-only resuscitation group, using the Parkland formula to calculate initial fluid requirements and measured intra-abdominal pressures [20]. Although they did not find an improvement in overall outcomes using plasma resuscitation, they did show a reduction in overall fluid loading and significantly lower intra-abdominal pressures $(26.5$ vs. $10.6 \mathrm{mmHg}, P<0.0001)$ in the plasmatreated group.

Hypertonic saline is an alternative to colloid, potentially reducing fluid shift to the interstitium. A doubling in mortality has been reported as well as a fourfold increase in renal failure, but a Cochrane Review was unable to ascertain whether there was any effect on patients with trauma, with burns or undergoing surgery due to lack of data [21,22]. Hypertonic saline is rarely used in our routine practice.

Currently, there is emerging evidence favouring routine use of colloid in managing burn shock. Colloid may 
reduce oedema-related complications and fluid creep particularly in those with increasing fluid requirements during resuscitation. Further studies are required to determine the most appropriate colloid, formulation and timing for its use.

\section{Pharmacological resuscitation}

There are no pharmacological agents currently in widespread clinical use. Attempts to reduce the severity of burn shock by blocking some of the chemical mediators of acute inflammation have been made with some success in clinical burns resuscitation. Such agents include hydralazine (a vasodilator), ketanserin (serotonin antagonist), hydrocortisone and ibuprofen (anti-inflammatory agent). Interestingly, a randomised prospective study involving 37 patients where vitamin $\mathrm{C}$ was given in ultrahigh doses reduced fluid requirements by $40 \%$ in burn shock and significantly reduced the ventilation time (21.3 vs. 12.1 days, $P<0.05)[23]$.

\section{Transfusion, coagulation and blood products}

The Transfusion Requirements in Critical Care study by the Canadian Clinical Trials Group prospectively randomised critically ill patients to a restrictive strategy of red cell transfusion (maintenance of haemoglobin at 7 to $9 \mathrm{~g} / \mathrm{dl}$ ) or a liberal strategy (maintenance of haemoglobin at 10 to $12 \mathrm{~g} / \mathrm{dl}$ ). Unfortunately this study excluded burns. The study found the restrictive strategy to be at least as effective as a liberal strategy with the possible exception of patients with acute myocardial infarction and unstable angina [24]. Following a multiple-centre cohort analysis highlighting an increased mortality associated with blood transfusion, there is increasing implementation of a restrictive transfusion strategy [25].

Implementation of a restrictive transfusion policy appears to have not adversely affected outcome in paediatric or adult burn patients [26,27]. Palmieri and colleagues undertook a study evaluating the effects of transfusion on outcome and revealed that the mean haemoglobin level in patients receiving their first unit of blood was significantly lower outside the operating theatre ( 8.9 vs. $10.2 \mathrm{~g} / \mathrm{dl}, P<0.05)$, which is higher than that perceived in medical practice $(8.1 \mathrm{~g} / \mathrm{dl})[25,28]$. Nonsurvivors received significantly more blood transfusions than survivors $(17.9$ vs. $13, P<0.05)$. This association was found after adjusting for multiple variables including burn size using multi-logistical regression. Patients with larger transfusions and poorer outcomes also had larger burns so increased transfusion requirements may simply be a surrogate marker for the severity of burn injury. In addition, the total number of units transfused correlated with the number of infectious episodes (Spearman rank correlation $=0.647 ; P<0.01$ ) [25]. A prospective, randomised trial of restrictive (7 to
$8 \mathrm{~g} / \mathrm{dl}$ ) versus liberal (9 to $10 \mathrm{~g} / \mathrm{dl}$ ) blood transfusion policy in burns $>20 \%$ TBSA is currently being undertaken by the American Burn Association.

The burn patient will intermittently need surgery that may need large or massive transfusion, and sets the burn patient apart from the more general critical care patient. Red cells facilitate haemostasis through a rheological effect by pushing platelets to the periphery of the vessel lumen to better interface at the endothelium as well as through direct effects on platelet biochemistry. Haematocrit $<30 \%$ can therefore lead to significant extra blood loss [29].

Transfusion requirements also need to reflect the surgical and rehabilitation plan. If a large burn excision requiring major transfusion is planned, the patient needs to be optimised for theatre and a low starting haemoglobin concentration seems unwise. If patients are entering the rehabilitation phase, anaemia compromising relevant activities should be avoided: the consequences of delayed or impaired rehabilitation are profound in this patient group.

There has been considerable attention on the use of tranexamic acid to minimise perioperative blood loss and transfusion requirements. However, whilst the popularity of this strategy has increased - including anecdotally in burns - the randomised controlled trials to prove conclusive benefit do not exist in the burns literature.

\section{Inhalation injury}

Airway management and ventilator support are often instigated early in patients with severe burns. Respiratory failure in these patients may be multifactorial. Primary injury to the lungs and upper airway occurs due to direct thermal inhalation injury. Secondary injury can occur early, following activation of the systemic inflammatory response, or later, following the development of sepsis. Any pulmonary injury can be exacerbated by ventilatorassociated lung damage. Full thickness chest or abdominal wall burns can result in poor compliance and high inspiratory pressures.

Smoke inhalation injury occurs via several different mechanisms not just direct thermal injury to the respiratory tract mucosa. The type of injury sustained depends upon factors including the patient's underlying respiratory function, the properties (water solubility) of the fumes inhaled and the extent of exposure. The exact pathophysiology of lung injury following smoke inhalation injury is unclear. The classic complement cascade is thought to be activated, followed by intrapulmonary leukocyte aggregation and oxygen free radical release resulting in pulmonary oedema [30]. Nitric oxide inhibits hypoxic vasoconstriction and is a key component of the inflammatory cascade, giving rise to vasodilatation, ventilation/perfusion mismatch and diminished transpulmonary oxygen transfer [31,32]. 
In addition to the ongoing inflammatory cascades, casts formed from cellular debris, fibrin clots, polymorphonuclear leucocytes, mucous, mucin B5 and airway oedema are likely to cause airway obstruction contributing to respiratory failure [31-36]. Partially obstructed airways can lead to air trapping and hyperinflation. This overdistention leads to release of a neutrophil chemoattractant, IL-8. Following activation, neutrophils produce superoxide that reacts with nitric oxide and causes endothelial damage and increased vascular permeability. Coagulation factors within the exuded plasma, tissue factor released from pulmonary epithelial cells and alveolar macrophages initiate the extrinsic coagulation cascade with resultant fibrin deposition in the alveolar space - a hallmark of smoke inhalation-induced acute lung injury. Fibrin also has an inhibitory effect on surfactant, further compounding alveolar collapse.

Systemic toxins such as hydrogen cyanide can be a significant cause of mortality, characterised by signs of hypoxia despite adequate arterial oxygen tension. Various agents such as nitrates and hydroxycobalamin have been used, but some are themselves toxic, and there is little evidence from randomised trials to support their routine use. Carbon monoxide levels higher than 15 to $20 \%$ should be treated with $100 \%$ endotracheal oxygen. There is little consensus regarding parameters or indications for hyperbaric oxygen, and availability is limited [37].

\section{Ventilatory strategies}

In the general intensive therapy unit, the incidence of ventilator-associated lung injury has been reduced following introduction of lung-protective ventilator strategies using low tidal volumes and permitting a degree of hypercapnia [38]. Other adjunctive strategies, including maintenance of high positive end-expiratory pressure and prone positioning, have not shown any beneficial effect on outcome $[39,40]$.

High-frequency oscillatory ventilation (HFOV) is an unconventional form of mechanical ventilation that is increasingly being used in the management of oxygenation failure in adult ARDS. There is limited information regarding the use of HFOV following inhalation injury [41-43]. The unique features of smoke inhalation-induced lung injury may limit the use of HFOV: distal alveolal recruitment may be limited by small airways obstructed with carbonaceous debris, oedema and sloughing mucosa; gas trapping and associated hypercapnia may be difficult to manage with HFOV; and management of secretions can be problematic. The use of HFOV also makes the use of nebulised therapies and therapeutic bronchoscopy impractical. Cartotto and colleagues retrospectively reviewed patients with ARDS after smoke inhalation and those with burns without an inhalational injury that received rescue HFOV for ARDS-related oxygen failure [42]. Patients with an inhalational injury did not achieve a significant improvement in the partial pressure of oxygen/fractional inspired oxygen ratio until 72 hours of HFOV therapy, contrasting with those without an inhalational injury where there was a significant improvement in oxygenation within 8 hours. However, there was no predefined HFOV protocol and there were significant baseline differences between the groups, including timing of HFOV initiation and preHFOV positive end-expiratory pressure.

There are no studies to assess the use of HFOV as an early strategy in acute lung injury after thermal inhalation. Further prospective randomised control trials with well-defined strict protocols are required to guide usage of HFOV in ARDS following inhalation injury.

\section{Tracheostomy}

Evidence suggests percutaneous tracheostomy is safe in burn patients, but caution should be employed in those with severe head and neck burns or upper airway oedema because airway loss could result in serious complications [44]. Burn surgeons are experienced at these challenging tracheostomies and coordination of tracheostomy (closed or open) with grafting of the neck requires close communication with the surgeon. A retrospective review of adult patients following severe burn injury found patients with tracheostomy had a significantly shorter time to extubation; however, there was no difference in ventilator support, pneumonia prevalence, length of stay or mortality [45]. As with nonburn patients, there is no consensus as to the optimal timing of tracheostomy. Saffle and colleagues found no advantage in early tracheostomy [45], but there may be increased benefit in children [46]. Early tracheostomy is likely to benefit most those with major burns plus significant inhalation injury because they will require numerous surgical procedures and prolonged ventilation, and respiratory sepsis is almost inevitable.

\section{Pharmacologic ventilatory adjuncts}

Studies in burned animals and humans have revealed multiple possible therapeutic effects of glycosaminoglycans for thermal injury. Heparin reduces airway obstruction by potentiating antithrombin-III-mediated inactivation of thrombin and possibly by acting as a free radical scavenger. Multiple studies have shown intravenous and nebulised heparin to be effective [47]. Tissue plasminogen activator and antithrombin have comparable effects to heparin $[47,48]$. A small, retrospective, single-centre study with 30 patients using historical controls receiving the same ventilatory strategy found a $38 \%$ reduction in mortality (number needed to treat 2.7 ) and reduced lung injury scores when nebulised unfractionated heparin, $N$-acetylcysteine and albuterol sulphate were administered in comparison with albuterol 
sulphate alone [49]. A paediatric case series with historical controls found a significant reduction in mortality, incidence of atelectasis and reintubation rate in the group treated with an alternating regime of aerosolised heparin alternating with 20\% N-acetylcysteine solution [50]. A multicentre, prospective trial is needed to confirm this finding.

Nitric oxide has been used in burn patients to treat hypoxic pulmonary vasoconstriction and to improve ventilation/perfusion mismatches and therefore tissue oxygenation $[51,52]$. However, Enkhbaatar and colleagues have shown there is an increase in nitric oxide levels in lung tissue secondary to inhalation injury and that the resultant loss of hypoxic vasoconstriction worsens ventilation perfusion mismatch [53]. They examined the use of BBS-2 (intrinsic nitric oxide synthase inhibitor) on sheep and reported an improvement in pulmonary gas exchange and shunt fraction. The use of pharmacological adjuncts for the management of inhalation injury remains limited by the lack of commercial availability of some agents, a lack of human trials and confounding experimental results.

\section{Sepsis}

Following severe thermal injury, patients exhibit physiologic and metabolic responses with resultant persistent tachycardia, tachypnoea and rise in baseline core temperature. Virtually all patients therefore meet the criteria for the systemic inflammatory response syndrome, resulting in little discriminative value in the burn patient. The American Burn Association has produced consensus guidelines suggesting modified definitions for utilising the systemic inflammatory response syndrome criteria in burn patients (Table 1) [54]. Other reliable markers of diagnosing sepsis are required. Those markers most commonly used include white cell count, C-reactive protein and erythrocyte sedimentation rate. More recently, procalcitonin has been described as a useful marker for sepsis in burn patients and in some studies has been found to be superior to C-reactive protein [5558]. In the paediatric setting, however, procalcitonin lagged behind clinical diagnosis by 0.8 days and was less useful than C-reactive protein [59].

Sepsis prevention is critical in the management of the severely burned patient. In addition to standard infection control measures, early excision and skin grafting is now accepted practice. A meta-analysis comparing early excision and conservative management with late grafting identified six studies that met their inclusion criteria. Two of these studies used sepsis as an outcome measure but used different definitions of sepsis, making comparison difficult. One study showed the early excision group required a shorter duration of antibiotic therapy and had fewer positive wound cultures [60].
Split skin grafting may be limited by the availability of donor sites in extensive burns. In this case, wound care should be optimised with a dermal substitute or appropriate dressing. Silver is a broad-spectrum antimicrobial whose properties are utilised by a number of topical preparations and dressings. Meshing of autografts allows for greater wound cover whilst limiting the donor area. Cadaveric allograft, often in combination with autograft in a sandwich technique, is seen by many as the best available temporising measure and grafts retain immunological function. The huge expense of allograft and its preorder for surgery adds another dimension for communication between intensivists, anaesthetists and surgeons lest product is wasted.

In adults, there is no role for prophylactic antibiotics unless utilised for wound excision or manipulation procedures due to the risks of adverse events and antimicrobial resistance. A systematic review and metaanalysis found a potential benefit of prophylactic antibiotics in burn patients but from data of poor methodological quality [61]. Selective decontamination of the digestive tract (SDD) in burns is generally supported by a small number of studies: a double-blind randomised control trial of 117 adult burn patients showed a significant reduction in both mortality and pneumonia in the treatment group with respect to placebo without adverse effects [62]. A recent metaanalysis of the three published SDD randomised control trials in burn patients, recruiting 440 patients (289 SDD patients, 151 controls), confirmed that SDD significantly reduced mortality by $78 \%(P<0.001)$ [63]. Other studies have found a reduction in wound colonisation with the administration of SDD [64,65]. A small paediatric randomised control trial did not find any significant differences in rates of colonisation, pneumonia or sepsis [66].

Burns sepsis needs rapid recognition and treatment with appropriate antibiotics, guided where available by microbiological results. Large burns are associated with fungal colonisation and infection so additional investigation and antifungals may be required. Multidrugresistant organisms are becoming an increasing problem in the burn care setting. Topical antibiotics may offer some efficacy against these organisms and can be used in conjunction with systemic antimicrobials. Alternatively, drugs with less well tolerated profiles may be required, such as colistin for the treatment of multi-resistant acinetobacter species.

The pharmokinetics of many drugs can be altered due to the physiologic changes following major burns. Altered pharmokinetics of major antibiotic classes can result in subtherapeutic levels of the drug $[67,68]$. Consideration should be given to reduced dosing intervals or the use of continuous infusions guided by appropriate monitoring, to ensure therapeutic plasma levels. 


\begin{tabular}{l} 
Table 1. American Burn Association suggested definitions \\
for utilising systemic inflammatory response syndrome \\
criteria in burn patients \\
\hline The sepsis trigger in adult burn patient includes at least three of the \\
following: \\
Temperature $>39^{\circ} \mathrm{C}$ or $<36.5^{\circ} \mathrm{C}$ \\
Progressive tachycardia \\
Adults $>110$ bpm \\
Progressive tachypnoea \\
$>25$ bpm not ventilated \\
Minute ventilation $>12 \mathrm{l} /$ minute ventilated \\
Thrombocytopaenia (not applicable until 3 days after initial resuscitation) \\
Adults $<100,000 / \mu l$ \\
Hyperglycaemia (absence of pre-existing diabetes mellitus) \\
Untreated plasma glucose $>200$ mg/dl \\
Insulin resistance $>7$ units/hour insulin intravenous drip \\
$>25 \%$ increase in insulin requirements over 24 hours \\
Inability to continue enteral feed $>24$ hours \\
Abdominal distention \\
Residual volume $2 \times$ feeding rate \\
Diarrhoea $>2,500$ ml/day \\
\hline
\end{tabular}

There is limited evidence to support routine use of corticosteroids in burn patients with sepsis [69,70]. The Surviving Sepsis Campaign recommends intravenous hydrocortisone should be used in patients with septic shock only if they are poorly responsive to both fluid resuscitation and inotropic support because there is a paucity of evidence showing a reduction in mortality plus the possibility of a higher incidence of secondary infection [71].

There remains controversy regarding the use of immune-enhancing dietary supplements. Studies have reported variable results following the use of glutamine supplementation. Current evidence from nine randomised control trials supports the use of enteral glutamine supplementation for patients with severe burn injuries [72]. Improvements were seen in wound healing, gut permeability, length of stay and mortality but there was heterogeneity between studies in both methodology and reporting. Further investigation is required to answer questions regarding dosage, timing, and length of supplementation. Research to date has provided insufficient evidence to support the use of other immunonutrients such as fish oil or arginine. Currently, there are no clinically approved topical immunomodulators available for the burn patient.

\section{Nutrition and hyperglycaemia}

Patients following a severe burn injury are hypermetabolic with resultant protein loss and reduction in lean body mass and hyperglycaemia through some of the same mechanisms as other critically ill trauma patients. Whilst the hypermetabolic state provides glucose to glucose-dependent tissues, it ultimately contributes to immune dysfunction, sepsis and organ failure. Holm and colleagues identified increased adverse outcome in adults following hyperglycaemia in the first 48 hours post injury [73]. The paediatric burn literature showed that hyperglycaemia is associated with increased catabolism, bacteraemia/fungaemia, skin graft loss and mortality whilst intensive insulin therapy was associated with survival [74-78].

The Normoglycaemia in Intensive Care Evaluation and Survival Using Glucose Algorithm Regulation Investigators assessed glucose targets in a mixed ICU population, using intensive insulin control versus conventional insulin control (4.5 to 6 vs. 8 to $10 \mathrm{mmol} / \mathrm{l})$ in more than 6,000 patients and reported lower mortality in the conventional group (24.9 vs. $27.5 \%, P=0.02)$ [78]. Following subgroup analysis, however, the trauma group (not stipulated whether this included patients with burns) benefited from tight glycaemic control. Control of hyperglycaemia can be difficult in burn patients and intensive insulin treatment can lead to a higher risk of hypoglycaemia, which can be compounded by frequent trips to theatre and breaks in enteral feed [79]. Cochrane and colleagues evaluated an intensive insulin protocol (aiming to maintain glucose $<12 \mathrm{mmol} / \mathrm{l}$ ) in 30 patients, 17 with burns and 13 with soft tissue infections [80]. They experienced a $5 \% /$ day rate of hypoglycaemic episodes (glucose $<6 \mathrm{mmol} / \mathrm{l}$ ) but reported no neurological sequelae or deaths. Studies examining the effect of tight glycaemic control in burns are limited, but mortality benefits as evidenced by Van den Berghe and colleagues [81] and others has led to the control of hyperglycaemia becoming a standard of care.

Insulin has additional immunomodulatory effects beyond increasing cellular uptake of glucose. Insulin has a trophic effect on mucosal and skin barriers, reducing bacterial invasion and translocation, improves wound matrix formation and inhibits the production of proinflammatory mediators.

Failure to satisfy the nutritional requirements of the hypermetabolic burn patient will lead to impaired wound healing, susceptibility to infection, organ failure and death [82-85]. A host of formulae to calculate calorific needs are used, and various feeding formulations are available. In general, the evidence greatly favours enteral to parenteral nutrition in relation to outcome measures and cost.

Nasogastric and nasojejunal feeding each have their proponents, with the advocates of duodenal feeding citing the ability to continue feed during surgical procedures without risk of aspiration, although reduced aspiration with intestinal feeding has not been proven [86,87]. 
Duodenal placement remains a challenging and inexact science requiring assistance with some imaging modality, but technological advancements have aided this at the bedside and many centres are moving towards jejunal feeding whether by fashion or evidence. Pro-motility agents such as erythromycin are often employed to assist maintenance of tubes in the correct location. Highquality evidence in many areas of nutrition remains very limited.

The combination of aggressive fluid resuscitation, early enteral feeding and proton pump inhibitors has reduced the incidence of acute gastrointestinal ulceration (Curling's ulcer) from 15\% to 3\% with a sizeable decrease in mortality from former death rates of $70 \%$ [88].

\section{Hypermetabolism}

Burn-induced catabolism results in accelerated protein breakdown and reduced protein synthesis, culminating in a negative net nitrogen balance. Demling and DeSanti reported that oxandrolone (an oral anabolic agent) improved weight gain and was an unquantified measure of muscle function [89], and in a later study showed a reduction in weight loss, urinary nitrogen loss and a shortened time to wound healing [90]. A prospective multicentre randomised double-blind trial of 81 patients with burns of 20 to $60 \%$ TBSA found that starting enteral oxandrolone 5 days post injury significantly reduced the hospital stay (45.3 vs. 32 days, $P=0.035)$ without significant adverse events [91].

The hypermetabolic response is in part mediated by endogenous catecholamines: shortly after severe burn or trauma, plasma catecholamine levels can increase up to 10 -fold [92]. $\beta$-blockade following severe burns can reduce supraphysiologic thermogenesis, tachycardia, cardiac work and resting energy expenditure. Herndon and colleagues conducted a prospective randomised control trial in paediatric patients with severe burns to evaluate the effect of propanolol on muscle catabolism [93]. The net muscle-protein balance increased by $82 \%$ from baseline values in the propanolol group $(P=0.002)$ and was significantly higher with respect to the control group $(P=0.001)$. The mechanism of action of propanolol remains unclear but appears to be a result of increased protein synthesis during a period of persistent protein breakdown and reduced peripheral lipolysis [94].

\section{Acute kidney injury}

Acute kidney injury (AKI) is common following a burn injury with an incidence as high as $30 \%$ but is associated with a reported mortality of between 80 and 100\% [95-97]. When defined by the Risk, Injury, Failure, Loss and End-stage kidney classification [98], AKI occurred in one-quarter of patients with severe burn injury (median mortality of $34.9 \%$ ); and when defined by the need for renal replacement therapy, AKI occurred in 3\% (median mortality of 80\%) [99]. Mortality increases in a stepwise fashion with increasing Risk, Injury, Failure, Loss and End-stage class [95,100]. Steinvall and colleagues reported approximately one-half of patients, particularly those with a severe burn injury, developed AKI during the first week post injury and the remaining patients during the second week [101]. In the majority of these patients, AKI was preceded by other organ dysfunction or sepsis. The burn shock resuscitation protocol used was successful at preventing early hypovolaemic AKI. This suggests that renal ischaemia, at least in the acute phase of burn shock, has a limited role in the development of AKI. Mosier and colleagues reported that both patients with or without an AKI averaged a urine output within the recommended 0.5 to $1.0 \mathrm{ml} / \mathrm{kg} /$ hour or greater; however, those who developed early AKI had a significantly lower average urine output (0.6 vs. $1.16 \mathrm{ml} /$ kg/hour, $P<0.01$ ) [102].

A study looking at acute respiratory dysfunction in patients with major burns revealed that ARDS occurs early, usually within 3 days, and that renal dysfunction was more common amongst those with the most severe respiratory dysfunction [103]. In sepsis, there is increasing evidence to suggest that inflammation and apoptosis play a key role in the aetiology of AKI [104] the literature in burns is limited. Late-onset AKI has been strongly associated with sepsis in the past [105]. A recent prospective cohort study found septic episodes were not always followed by renal dysfunction and two-thirds of late-onset AKI was not preceded by sepsis [101]. The development of intra-abdominal hypertension and abdominal compartment syndrome following overresuscitation may contribute to AKI of later onset. Exposure to nephrotoxic antibiotics and intravenous contrast may also have a role.

Aggressive utilisation of continuous renal replacement therapy $(50.2 \pm 13.2 \mathrm{ml} / \mathrm{kg} /$ hour $)$ in severely burned casualties with AKI significantly improved survival [106]. A recent study of patients with severe burn injury defined as TBSA $>40 \%$ with AKI treated with continuous venovenous haemofiltration with a maintenance dose of 20 to $35 \mathrm{ml} / \mathrm{kg} /$ hour compared with historical controls prior to the availability of continuous venovenous haemofiltration found the use of continuous venovenous haemofiltration to be associated with a reduction in 28 -day stay (38 vs. $71 \%, P=0.011$ ) and hospital mortality (62 vs. $86 \%, P=0.04$ ) [107]. Significant clinical improvements were seen in those with respiratory dysfunction and shock. The American Burn Association's randomised controlled evaluation of haemofiltration in adult burn patients with septic shock and acute renal failure (RESCUE) is currently recruiting patients as of May 2013. 


\section{Conclusion}

Regional burn centres have developed to address resource requirements and the complexity of burn care. There have been significant improvements in outcome following burn injuries in the latter half of the 20th century, reflecting advances in critical care - in particular, following the introduction of fluid resuscitation protocols, early burn excision and closure, antimicrobials and infection control, nutritional support and modulation of the metabolic response. These improvements in care have resulted in the majority of patients outside extremes of age treated in a modern burn centre being expected to survive [108]. The US national burn repository with reports submitted from 91 hospitals showed that the length of stay has reduced in the past 10 years from approximately 11 days to 9 days, and mortality has fallen in females from $6.8 \%$ to $3.6 \%$ and in males from $4.5 \%$ to approximately $3 \%$ [109].

Recent evidence suggests the routine use of colloid resuscitation and permissive hypovolaemia to reduce fluid creep and its attendant complications. Whilst many strategies including oxandralone have been utilised successfully to attenuate the hypermetabolic response, further studies are required to assess their safety and appropriate use. Currently, $\beta$-blockade using propanolol appears to be the most efficacious anti-catabolic therapy. At the Mersey Regional Burn Centre we have adopted the routine use of oxandrolone and have a fluid resuscitation protocol based on the Parkland formula but modified to 2 to $3 \mathrm{ml} / \mathrm{kg} / \%$ burn with albumin rescue [110]. Burns management is a rapidly evolving field with 8,000 burnsrelated articles in the last 10 years as compared with 11,000 in the last 90 years, with numerous studies underway that will hopefully provide further guidance for the management of these critically ill patients.

\section{Abbreviations}

AKI, acute kidney injury; ARDS, acute respiratory distress syndrome; HAS, human albumin solution; HFOV, high-frequency oscillatory ventilation; IL, interleukin; SDD, selective decontamination of the digestive tract; TBSA, total body surface area.

\section{Competing interests}

The authors declare that they have no competing interests.

\section{Author details}

'Department of Anaesthesia, University Hospital Aintree, Liverpool L9 7AL, UK. 2Department of Neuroanaesthesia and Critical Care, Horsley ICU, The Walton Centre for Neurology and Neurosurgery, Liverpool L9 7LJ, UK. IIntensive Care Unit, Whiston Hospital, Warrington Road, Prescot L35 5DR, UK. ${ }^{4}$ Mersey Regional Burns Unit, Whiston Hospital, Warrington Road, Prescot L35 5DR, UK.

Published: 7 October 2013

\section{References}

1. UK Burn Injury Data 1986-2007 First Report of the iBID [www.ibidb.org/downloads]

2. Brusselaers N, Monstrey S, Vogelaers D, Hoste E, Blot S: Severe burn aetiology in Europe: a systematic review of the incidence, aetiology, morbidity and mortality. Crit Care 2010, 14:R188.
3. Mitra B, Fitzgerald M, Cameron P, Cleland H: Fluid resuscitation in major burns. ANZ J Surg 2006, 76:35-38.

4. Barrow RE, Jeschke $M G$, Herndon DN: Early fluid resuscitation improves outcomes in severely burned children. Resuscitation 2000, 45:91-96.

5. Collis N, Smith G, Fenton OM: Accuracy of burn size estimation and subsequent fluid resuscitation prior to arrival at the Yorkshire Regional Burns Unit. A three year retrospective study. Burns 1999, 25:345-351.

6. Baxter C: Fluid volume and electrolyte changes in the early post-burn period. Clin Plastic Surg 1974, 1:693-703.

7. Holm C: Resuscitation in shock associated with burns. Tradition or evidence based medicine? Resuscitation 2000, 44:157-164.

8. Csontos C, Foldi V, Fischer T, Bogar L: Factors affecting fluid requirement on the first day after severe burn trauma. ANZ J Surg 2007, 77:745-748.

9. Kamolz LP, Andel H, Schramm W, Meissel G, Herndon DN, Frey M: Lactate an early predictor of morbidity and mortality in patients with severe burns. Burns 2005, 31:986-990.

10. Jeng JC, Lee K, Jablonski K, Jordan MH: Serum lactate and base deficit suggest inadequate resuscitation of patients with burns injuries: application of point-of-care laboratory instrument. J Burn Care Rehabil 1997, 18:402-405.

11. Saffle JR: The phenomenon of 'fluid creep' in acute burn resuscitation. J Burn Care Res 2007, 28:382-395

12. Holm C, Mayr M, Tegeler J, Horbrand F, Henckel von Donnersmarck G, Muhlbauer W, Pfeiffer UJ: A clinical randomised study on the effects of invasive monitoring on burn shock resuscitation. Burns 2004, 30:798-807.

13. Pham TN, Cancio LC, Gibran NS: American Burn Association practice guidelines. Burn shock resuscitation. J Burn Care Res 2008, 29:257-266.

14. Arlati S, Storti E, Pradella V, Bucci L, Vitolo A, Pulici M: Decreased fluid volume to reduce organ damage: a new approach to burn shock resuscitation. A preliminary study. Resuscitation 2007, 72:371-378.

15. Pruitt BA: Protection from excessive resuscitation 'Pushing The Pendulum Back. J Trauma 2000, 49:567-568.

16. Alderson P, Bunn F, Lefebvre C, Li WP, Li L, Roberts I, Schierhout G: Human albumin solution for resuscitation and volume in critically ill patients. Cochrane Database Syst Rev 2002, 1:CD001208.

17. Goodwin CW, Dorethy J, Lam V, Pruitt BA: Randomised trial of efficacy of crystalloid and colloid resuscitation on haemodynamic response and lung water following thermal injury. Ann Surg 1983, 197:520-531.

18. Cooper AB, Cohn SM, Zhang HS, Hanna K, Stewart TE, Slutsky AS: Five percent albumin for adult burn shock resuscitation: lack of effect on daily multiple organ dysfunction. Transfusion 2006, 46:80-89.

19. Cochran A, Morris SE, Edelman LS, Saffle JR: Burn patient characteristics and outcomes following resuscitation with albumin. Burns 2007, 33:25-30.

20. O'Mara MS, Slater H, Goldfarb IW, Saushaj PF: A prospective, randomised evaluation of intra-abdominal pressures with crystalloid and colloid resuscitation in burn patients. J Trauma 2005, 58:1011-1018.

21. Huangg PP, Stucky FS, Dimick AR, Traet RC, Bessey PQ, Rue LW: Hypertonic sodium resuscitation is associated with renal failure and death. Ann Surg 1995, 221:543-554

22. Bunn F, Roberts I, Tasker R, Akpa E: Hypertonic versus near isotonic crystalloid for fluid resuscitation in critically ill patients. Cochrane Database Syst Rev 2004, 3:CD002045.

23. Tanaka H, Matsuda T, Miyagantani Y, Yukioka T, Matsuda H, Shimazaki S: Reduction of resuscitation fluid volumes in severely burned patients using ascorbic acid administration: a randomised, prospective study. Arch Surg 2000, 135:326-331

24. Herbert PC, Wells G, Blajchman MA, Marshall J, Martin C, Pagliarello G, Tweedale M, Schweitzer I, Yetisir E; Transfusion Requirements in Critical Care Investigators: A multi-centre, randomised, controlled clinical trial of transfusion requirements in critical care: Transfusion Requirements in Critical Care Investigators. Canadian Critical Care Trials Group. N Engl J Med 1999, 340:409-417

25. Palmieri TL, Caruso DM, Foster KN, Cairns BA, Peck MD, Gamelli RL, Mozingo DW, Kagan RJ, Wahl W, Kemalyan NA, Fish JA, Gomez M, Sheridan RL, Faucher LD, Latenser BA, Gibran NS, Klein RL, Solem LD, Saffle JR, Morris SE, Jeng JC, Voigt D, Howard PA, Molitor F, Grennhalgh DG: Effect of blood transfusion on outcome after major burn injury: a multi-centre study. Crit Care Med 2006, 34:1602-1607.

26. Palmieri TL, Lee T, O'Mara MS, Greenhalgh DG: Effects of a restrictive blood transfusion on outcomes in children with burn injury. J Burn Care Res 2007, 28:65-70. 
27. Kwan P, Gomez M, Cartotto R: Safe and successful restriction of transfusion in burn patients. J Burn Care Res 2006, 27:826-834.

28. Palmieri TL, Greenhalgh DG: Blood transfusion in burns: what do we do? J Burn Care Rehabil 2004, 25:71-75.

29. Hardy JF, De Moerloose P, Samama M: Massive transfusion and coagulopathy: pathophysiology and implications for clinical management. Can J Anaesth 2004; 51:293-310.

30. Enkhbaatar P, Traber DL: Pathophysiology of acute lung injury in combined burn and smoke inhalation injury. Clin Sci 2004, 107:137-143.

31. Murakami K, Traber DL: Pathophysiological basis of smoke inhalation injury. News Physiol Sci 2003, 18:125-129.

32. Hill IR: Reactions to particles in smoke. Toxicology 1996, 115:119-122.

33. Cox RA, Mlcak RP, Chinkes DL, Jacob S, Enkhbaatar P, Jaso J, Parish LP, Traber DL, Jeschke MG, Herndon DN, Hawkins HK: Upper airway mucus deposition in lung tissue of burn trauma victims. Shock 2008, 29:356-361.

34. Saliba MJ: Heparin in the treatment of burns: a review. Burns 2001, 27:349-358.

35. Fitzpatrick JC, Cioffi WG, Cheu HW, Pruitt BA Jr: Predicting ventilation failure in children with inhalation injury. J Paediatr Surg 1994, 29:1122-1126.

36. Ventilation with lower tidal volumes as compared with traditional tidal volumes for acute lung injury and the acute respiratory distress syndrome. The Acute Respiratory Distress Syndrome Network. N Engl J Med 2000, 342:1301-1308

37. Kealey GP: Carbon monoxide toxicity. J Burn Care Res 2009; 301:146-147.

38. ARDS Network: Higher versus lower positive end-expiratory pressures in patients with acute respiratory distress syndrome. N Engl J Med 2004, 351:327-336.

39. Gattinoni L, Tognoni G, Pesenti A, Taccone P, Mascheroni D, Labarta V, Malacrida R, Di Gulio P, Fumagalli R, Pelosi P, Brazzi L, Latini R; Prone-Supine Study Group: Effect of prone positioning on the survival of patients with acute respiratory failure. N Eng/ J Med 2001, 345:568-573.

40. Cioffi WG, deLemos RA, Coalson JJ, Gerstmann DA, Pruitt BA: Decreased pulmonary damage in primates with inhalation injury treated with high frequency ventilation. Ann Surg 1993, 218:328-337.

41. Jackson MP, Philip B, Murdoch LJ, Powell BWEM: High frequency oscillatory ventilation successfully used to treat a severe paediatric inhalation injury. Burns 2002, 28:509-511.

42. Cartotto R, Walia G, Ellis S, Gomez M, Fowler R: Oscillation after inhalation: high frequency oscillatory ventilation in burn patients with acute respiratory distress syndrome and coexisting inhalation injury. J Burn Care Res 2009, 30:119-127.

43. Cooper AB, Islur A, Gomez M, Goldenson GL, Cartotto RC: Hypercapnic respiratory failure and partial upper airway obstruction during high frequency oscillatory ventilation in an adult burn patient. Can J Anaesth 2002, 49:724-728

44. Gravvanis Al, Tsoutsos DA, Iconomou TG, Papadopoulos SG: Percutaneous versus conventional tracheostomy in burned patients with inhalation injury. World J Surg 2005, 29:1571-1575.

45. Saffle JR, Morris SE, Edelman L: Early tracheostomy does not improve outcome in burn patients. J Burn Care Rehabil 2002, 23:431-438.

46. Palmieri TL, Jackson W, Greenhalgh DG: Benefits of early tracheostomy in severely burned children. Crit Care Med 2002, 30:922-924.

47. Bartley AC, Edgar DW, Wood FM: Pharmaco-management of inhalation injuries for burn survivors. Drug Des Devel Ther 2008, 2:9-16.

48. Enkhbaatar P, Murakami K, Cox C, Westphal M, Morita N, Brantley K, Burke A, Hawkins H, Schmalstieg F, Traber L, Herndon D, Traber D: Aerosolised tissue plasminogen inhibitor improves pulmonary function in sheep with burn and smoke inhalation. Shock 2004, 22:70-75.

49. Miller AC, Rivero A, Ziad S, Smith DJ, Elamin EM: Influence of nebulised unfractionated heparin and $\mathrm{N}$-acetylcystine in acute lung injury after smoke inhalation injury. J Burn Care Res 2009, 30:249-256

50. Desai MH, Mlcak R, Richardson J, Nichols R, Herndon DN: Reduction in mortality in paediatric patients with inhalation injury with aerosolised heparin/N-acetylcysteine therapy. J Burn Care Rehabil 1998, 19:210-212.

51. Sheridan RL, Hurford WE, Kacmarek RM, Ray H, Yin LM, Ryan CM, Tompkins RG: Inhaled nitric oxide in burn patients with respiratory failure. J Trauma 1997, 42:629-634.

52. Westphal M, Cox RA, Traber LD, Morita N, Enkhbaatar P, Schmalstieg FC, Hawkins HK, Maybauer DM, Maybauer MO, Murakami K, Burke AS, WestphalVarghese BB, Rudloff HE, Salsbury JR, Jodin JM, Lee S, Traber DL: Combined burn and smoke inhalation injury impairs ovine hypoxic pulmonary vasoconstriction. Crit Care Med 2006, 34:1428-1436

53. Enkhbaatar P, Murakami K, Shimoda K, Mizutani A, Traber L, Phillips G, Parkinson J, Salsbury JR, Biondo N, Schmalstieg F, Burke A, Cox R, Hawkins H, Herndon D, Traber D: Inducible nitric oxide synthase dimerization inhibitor prevents cardiovascular and renal morbidity in sheep with combined burn and smoke inhalation injury. Am J Circ Physiol 2003, 285:H2430-H2436.

54. Greenhalgh DG, Saffle JR, Holmes JH, Gamelli RL, Palmieri TL, Horton JW, Tompkins RG, Traber DL, Mozingo DW, Deitch EA, Goodwin CW, Herndon DN Gallagher JJ, Sanford AP, Jeng JC, Ahrenholz DH, Neely AN, O'Mara MS, Wolf SE, Purdue GF, Garner WL, Yowler CJ, Latenser BA: American Burn Association consensus conference to define sepsis and infection in burns. J Burn Care Res 2007, 28:776-790.

55. Von Heimburg D, Stieghorst W, Khorram-Sefat R, Pallua N: Procalcitonin a sepsis parameter in severe burn injuries. Burns 1998, 24:745-750.

56. Bargues $L$, Chancerelle Y, Catineau J, Jault P, Carsin H: Evaluation of serum procalcitonin in the ICU following severe burns. Burns 2007, 33:860-864.

57. Barati M, Alinejad F, Bahar MA, Tabrisi MS, Shamshiri AR, Bodouhi NOL, Karimi $\mathrm{H}$ : Comparison of WBC, ESR, CRP and PCT serum levels in septic and nonseptic burn cases. Burns 2008, 34:770-774.

58. Lavrentieva A, Kontakiotis T, Lazaridis L, Tsotsolis N, Koumis J, Kyriazis G, Bitzani M: Inflammatory markers in patients with severe burn injury. What is the best indicator of sepsis? Burns 2007, 33:189-194

59. Neely AN, Fowler LA, Kagan RJ, Warden GD: Procalcitonin in paediatric burn patients: an early indicator of sepsis. J Burn Care Rehabil 2004, 25:76-80

60. Ong YS, Samuel M, Song C: Meta-analysis of early excision of burns. Burns 2006, 32:145-150.

61. Avni T, Levcovich A, Ad-El DD, Leibovici L, Paul M: Prophylactic antibiotics for burn patients: systemic review and meta-analysis. BMJ 2010, 340:c241

62. De La Cal MA, Cerda E, Garcia-Hierro P, van Saene HKF, Gomez-Santos D, Negro E, Lorente JA: Survival benefit in critically ill burned patients receiving selective decontamination of the digestive tract: a randomised placebo-controlled, double blind trial. Ann Surg 2005, 23:424-430.

63. Silvestri L, de la Cal MA, Taylor N, van Saene HKF, Parodi PC: Selective decontamination of the digestive tract in burn patients: an evidence based manoeuvre that reduces mortality. J Burn Care Res 2010, 31:372-373.

64. Mackie DP, van Hertum WA, Schumberg TH, Kujiper EC, Knape P, Massaro F: Reduction in staphylococcus aureus wound colonisation using nasal mupirocin and selective decontamination of the digestive tract in extensive burns. Burns 1994, 20(Suppl 1):S14-S17.

65. Manson WL Kasen HJ, Sauer EW, Olieman A: Selective intestinal decontamination for prevention of wound colonisation in severely burned patients: a retrospective analysis. Burns 1992, 18:98-102.

66. Barret JP, Jeschke MG, Herndon DN: Selective decontamination of the digestive tract in severely burned paediatric patients. Burns 2001, 27:439-445.

67. Conil JM, Georges B, Lavit M, Seguin T, Tack I, Samii K, Chabanon G, Houin G, Saivin S: Pharmokinetics of ceftazidime and cefepime in burn patients: the importance of age and creatinine clearance. J Clin Pharmacol Ther 2007, 45:529-538.

68. Lovering AM, Le Froch R, Hovsepian L, Stephanazzi J, Bret P, Birraux G, Vinsonneau C: Pharmokinetic evaluation of linezolid in patients with thermal injuries. J Antimicrob Chemother 2009, 63:553-559.

69. Fuchs P, Bozkurt A, Johnen D, Smeets R, Groger A, Pallua N: Beneficial effects of corticosteroids in catecholamine-dependent septic burn patients. Burns 2007, 33:306-311.

70. Winter W, Kamolz L, Donner A, Hoerauf K, Blaicher A, Andel H: Hydrocortisone improved haemodynamics and fluid requirement in surviving but not in non-surviving of severely burned patients. Burns 2003, 29:717-720

71. Dellinger RP, Levy MM, Carlet JM, Bion J, Parker MM, Jaeschke R, Reinhart K, Angus DC, Brun-Buisson C, Beale R, Calandra T, Dhainaut JF, Gerlach H, Harvey M, Marini JJ, Marshall J, Ranieri M, Ramsay G, Sevransky J, Thompson BT, Townsend S, Vender JS, Zimmerman JL, Vincent JL; International Surviving Sepsis Campaign Guidelines Committee; American Association of CriticalCare Nurses; American College of Chest Physicians; American College of Emergency Physicians; Canadian Critical Care Society; European Society of Clinical Microbiology and Infectious Diseases; et al: Surviving Sepsis Campaign: international guidelines for management of severe sepsis and septic shock. Crit Care Med 2008, 36:296-327.

72. Kurmis R, Parker $A$, Greenwood J: The use of immunonutrition in burn injury care: where are we? J Burn Care Res 2010, 31:677-691. 
73. Holm C, Horbrand F, Mayr M, von Donnersmarck GH, Muhlbauer W: Acute hyperglycaemia following thermal injury: friend or foe? Resuscitation 2004, 60:71-77.

74. Mowlavi A, Andrews K, Milner S, Herndon DR, Heggers JP: The effects of hyperglycaemia on skin graft survival in the burn patient. Ann Plast Surg 2000, 45:629-632.

75. Gore DC, Chinkes DL, Hart DW, Wolf SE, Herndon DN, Sanford AP: Hyperglycaemia exacerbates muscle protein catabolism in burn injured patients. Crit Care Med 2002, 30:2438-2442.

76. Gore DC, Chinkes DL, Heggers J, Herndon DN, Wolf SE, Desai M: Association of hyperglycaemia with increased mortality after severe burn injury. J Trauma 2001, 51:540-544.

77. Pham TN, Warren AJ, Phan HH, Molitor F, Greenhalgh DG, Palmieri TL: Impact of tight glycaemic control in severely burned children. J Trauma 2005 59:1148-1154.

78. Finfer S, Chittock DR, Su SY, Blair D, Foster D, Dhingra V, Bellomo R, Cook D, Dodek P, Henderson WR, Herbert PC, Heritier S, Heyland DK, McArthur C, McDonald E, Mitchell I, Myburgh JA, Norton R, Potter J, Robinson BG, Ronco $\mathrm{J}$; NICE-SUGAR Study Investigators: Intensive versus conventional glucose control in critically ill patients. N Engl J Med 2009, 360:1283-1297.

79. Mecott GA, Al-Mousawi AM, Gauglitz GG, Herndon DN, Jeschke MG: The role of hyperglycaemia in burned patients: evidence based studies. Shock 2010, 33:5-13.

80. Cochrane A, Davis L, Morris SE, Saffle JR: Safety and efficacy of an intensive insulin protocol; in a burn trauma intensive care unit. J Burn Care Res 2008 29:187-191.

81. Van den Bergh, Wouters P, Weekers F, Verwaest C, Bruyninckx F, Schetz M, Vlasselaers D, Ferdinande P, Lauwers P, Bouillon R: Intensive insulin therapy in the critically ill patient. N Engl J Med 2001, 345:1359-1367.

82. Alverdy J, Aoys E, Moss G: Total parenteral nutrition promotes bacterial translocation from the gut. Surgery 1988, 104:185-190.

83. Kudsk KA, Croce MA, Fabian TC, Minard G, Tolley EA, Poret HA, Kuhl MR, Brown RO: Enteral vs. parenteral feeding: effects on septic morbidity following blunt and penetrating abdominal trauma. Ann Surg 1992, 215:503-508.

84. Saito H, Trocki O, Alexander JW, Kopcha R, Heyd T, Joffe SN: The effect of route of nutrient administration on the ntritional state, catabolic hormone secretion and gut mucosal integrity after burn injury. JPEN J Parenter Enteral Nutr 1987, 11:1-7.

85. Magnotti L, Deitch E: Burns, bacterial translocation, gut barrier function, and failure. J Burn Care Rehabil 2005, 26:383-391.

86. Kearns PJ, Chin D, Mueller L, Wallace K, Jensen WA, Kirsch CM: The incidence of ventilator-associated pneumonia and success in nutrient delivery with gastric versus small intestinal feeding: a randomized clinical trial. Crit Care Med 2000, 28:1742-1746.

87. Mentec H, Dupont H, Bocchetti M, Cani P, Ponche F, Bleichner G: Upper digestive intolerance during enteral nutrition in critically ill patients: frequency, risk factors, and complications. Crit Care Med 2001 29:1955-1961.

88. Raff T, Germann G, Hartmann B: The value of early enteral nutrition in the prophylaxis of stress ulceration in the severely burned patient. Burns 1997, 23:313-318.

89. Demling RH, DeSanti L: Oxandrolone, an anabolic steroid, significantly increases the rate of weight gain in the recovery phase after major burns. J Trauma 1997, 43:47-51.

90. Demling $\mathrm{RH}$ : Comparison of the anabolic effects and complications of human growth hormone and the testosterone analogue, oxandrolone, after severe burn injury. Burns 1999, 25:215-221.

91. Wolf SE, Edelman LS, Kemalyan N, Donison L, Cross J, Underwood M, Spence RJ, Noppenberger D, Palmieri TL, Greenhalgh DG, Lawless M, Voigt D, Edwards P, Warner P, Kagan R, Hatfield S, Jeng J, Crean D, Hunt J, Purdue G, Burris A, Cairns B, Kessler M, Klein RL, Baker R, Yowler C, Tutulo W, Foster K, Caruso D, Hildebrand B, et al:: Effects of oxandrolone on outcome measures in the severely burned: a multicentre prospective randomised double blind trial. J Burn Care Res 2006, 27:131-139.
92. Wilmore DW, Aulick LH: Metabolic changes in burned patients. Surg Clin North Am 1978, 58:1173-1187.

93. Herndon DN, Hart DW, Wolf SE, Chinkes DL, Wolfe RR: Reversal of catabolism by beta-blockade after severe burns. N Engl J Med 2001, 345:1223-1229.

94. Pereira CT, Jeschke MG, Herndon DN: Beta-blockade in burns. Novartis Found Symp 2007, 280:238-248.

95. Mustonen KM, Vuola J: Acute renal failure in intensive care burn patients. J Burn Care Res 2008, 29:227-237.

96. Leblanc $M$, Thibeault $Y$, Querin S: Continuous haemofiltration and haemodiafiltration for acute renal failure in severely burned patients. Burns 1997, 23:160-165.

97. Chrysopoulo MT, Jeschke MG, Dziewulski P, Barrow RE, Herndon DN: Acute renal dysfunction in severely burned adults. J Trauma 1999, 46:141-144.

98. Bellomo R, Ronco C, Kellum JA, Mehta RL, Palevsky O: Acute Dialysis Quality Initiative Workgroup. Acute renal failure - definition, outcome measures, animal models, fluid therapy and information technology needs: the second International Conference of the Acute Dialysis Quality Initiative (ADQI) Group. Crit Care 2004, 8:R204-R212.

99. Brusselaers N, Monstrey S, Colpaert K, Decruyenaere J, Blot SI, Hoste EA: Outcome of acute kidney injury in severe burns: a systematic review and meta-analysis. Intensive Care Med 2010, 36:915-925.

100. Coca SG, Bauling P, Schifftner T, Howard CS, Teitelbaum I, Parikh CR: Contribution of acute kidney injury toward morbidity and mortality in burns: a contemporary analysis. Am J Kidney Dis 2007, 49:517-523.

101. Steinvall I, Bak Z, Sjoberg F: Acute kidney injury is common, parallels organ dysfunction or failure, and carries appreciable mortality in patients with major burns: a prospective exploratory cohort study. Crit Care 2008, 12:R124.

102. Mosier MJ, Pham TN, Klein MB, Gibran NS, Arnoldo BD, Gamelli RL, Tompkins $R G$, Herndon DN: Early acute kidney injury predicts progressive renal dysfunction and higher mortality in severely burned adults. J Burn Care Res 2010, 31:83-92.

103. Steinvall I, Bak Z, Sjoberg F: Acute respiratory distress syndrome is as important as inhalation injury for the development of respiratory dysfunction in major burns. Burns 2008, 34:441-451.

104. Bellomo R, Di Giantomasso Wan L, D, Ronco C: The pathogenesis of septic acute renal failure. Curr Opin Crit Care 2003, 9:496-502.

105. Kim GH, Oh KH, Yoon JW, Koo JW, Kim HJ, Chae DW, Noh JW, Kim JH, Park YK: Impact of burn size and initial serum albumin level on acute renal failure occurring in major burn. Am J Nephrol 2003, 23:55-60.

106. Chung KK, Juncos LA, Wolf SE, Mann EE, Renz EM, White CE, Barillo DJ, Clark RA, Jones JA, Edgecombe HP, Park MS, Albrecht MC, Cancio LC, Wade CE, Holcomb JB: Continuous renal replacement therapy improves survival in severely burned military casualties with acute kidney injury. J Trauma 2008, 64(Suppl 2):S179-S185.

107. Chung KK, Lundy JB, Matson JR, Renz EM, White CE, King BT, Barillo DJ, Jones JA, Cancio LC, Blackbourne LH, Wolf SE: Continuous venovenous haemofiltration in severely burned patients with acute kidney injury: a cohort study. Crit Care 2009, 13:R62.

108. Pereira CT, Barrow RE, Sterns AM, Hawkins HK, Kimbrough CW, Jeschke MG, Lee JO, Sanford AP, Herndon DN: Age dependent differences in survival after severe burns: a unicentric review of 1674 patients and 174 autopsies over 15 years. J Am Coll Surg 2006, 202:536-548.

109. Bessey P, Caruso D, Casavant C, Edelman L, Jeng J, Kemalyan N, Lentz C, Reigart C, Schurr M: National Burn Repository. Report of Data from 2001-2010. American Burn Association; 2011. [http://www.ameriburn. org/2011NBRAnnualReport.pdf]

110. Mersey Burns [www.merseyburns.com]

\section{doi:10.1186/cc12706}

Cite this article as: Snell JA, et al:: Clinical review: The critical care

management of the burn patient. Critical Care 2013, 17:241. 